\title{
O RADIOJORNALISMO NA CIDADE DE PALMAS: Uma análise da atuação de seis rádios sobre suas contribuições para cidadania
} RADIOJORNALISM IN THE CITY OF PALMAS: an analysis of the performance of six radio stations about their contributions to citizenship

\author{
Valquíria Guimarães da SILVA ${ }^{1}$ \\ Universidade Federal do Tocantins | Brasil
}

\begin{abstract}
Resumo
Consideramos o rádio como um veículo privilegiado para a promoção da cidadania, já que reúne um conjunto de elementos favoráveis como a proximidade com o público e a linguagem utilizada. Desta forma, analisamos neste trabalho a relação entre cidadania e rádio na cidade de Palmas-TO. Para isso, estudamos as grades de programação de seis rádios com sintonia na cidade durante dois anos (2017 e 2018). Observamos que o rádio continua a ter um grande potencial cívico, mas neste momento, de um modo geral, a programação das seis rádios participantes do estudo, pouco contribuiu para a promoção de uma cidadania efetiva.

\section{Palavras-chave}

Cidadania; Palmas-TO; Jornalismo; Radiojornalismo; Democracia.

\section{Abstract}

We consider the radio as a privileged vehicle for the promotion of citizenship, since it brings together a set of favorable elements such as proximity to the public and the language used. Thus, in this work we analyze the relationship between citizenship and radio in the city of Palmas-TO. For this, we studied the brodcast programming of six radio stations tuned in the city for two years (2017 and 2018). We observed that the radio continues to have a great civic potential, but at this moment, in general, the programming of the six radios participating in the study, did little to promote effective citizenship.

\section{Keywords}

Citizenship; Palmas-TO; Journalism; Radiojournalism; Democracy.
\end{abstract}

${ }^{1}$ JORNALISTA. Doutora em Ciências da Comunicação pela Faculdade de Ciências Sociais e Humanas da Universidade Nova de Lisboa. Mestreem Educação e graduada em Comunicação Social - Jornalismo - pela UFPB. Professora Adjunta da UFT e atual coordenadora do Curso de Jornalismo. Contato: vguimaraes@uft.edu.br 


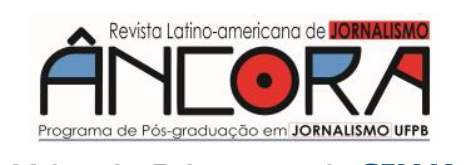

Valquíria Guimarães da SILVA

\section{Introdução}

o comemorarmos o centenário do rádio no Brasil e seu percurso
como o veículo de comunicação que trouxe o conceito de
comunicação de massa, pensamos nos vários desafios e transformações deste veículo, principalmente após a chegada da televisão e depois da Internet, o que para alguns autores foi entendido como um possível fim para o rádio.

No entanto, o rádio sobrevive até hoje e continua a desempenhar um papel importante nas sociedades, principalmente com relação à sua função formativa e de aproximação ao seu público, no que diz respeito às questões cotidianas dos cidadãos. "A rádio, apesar da concorrência de outros meios, possui um papel relevante na transmissão de conhecimentos aos indivíduos" (BONIXE, 2012, p. 176). Mesmo com a ampliação do desenvolvimento tecnológico e acesso aos novos meios de comunicação de massa, o rádio continua a possuir características de mobilidade que nenhum outro meio de comunicação possui, além da sua total interface com os outros meios.

Pensar a contribuição do rádio para a cidadania é pensar em sujeitos, em homens e mulheres como cidadãos e cidadãs. Habermas (2007, p. 35), argumenta que é necessário para a compreensão do ser cidadão e da cidadania, considerar que os cidadãos são pessoas que desenvolvem a sua identidade pessoal em determinados contextos, tradições e ambientes culturais específicos, e que precisam desses contextos para conservar a sua identidade. Cecília Peruzzo (1998, p. 158) entende a cidadania como um aprimoramento contínuo vinculado à aprendizagem propiciada pela vida cotidiana. Para a autora, a cidadania é uma construção social. E como construção social, considerar-nos-emos cidadãos à medida que tivermos consciência dessa nossa condição social. Para se discutir cidadania é necessário ter consciência dela, esta é a primeira condição: reconhecer os direitose deveres dos e para com os outros cidadãos. 
[...] cidadania é aqui compreendida como a dimensão ou capacitação humana que permite intervenção na realidade. Cidadão é aquele que, portanto, intervém na realidade. Ora, essa intervenção é possível, entre outros fatores, pela identificação ou não com esta realidade. Alguém que viva à margem, ou alheio à realidade que o cerca, não tem como nem porquês para intervir. Não estar alheio ou estar imerso na realidade depende, então, de reconhecê-la, saber dela, estar informado sobre ela. Assim temos, muito resumidamente, a importância da informação e a necessidade de se comunicar essa informação (TAVARES, 2008, p. 72).

Ao compreendermos que a cidadania é construída através da relação das pessoas com a sociedade em que vivem, entendemos que o fundamento do exercício da cidadania é a formulação de opiniões sobre os assuntos relevantes para a vida dos indivíduos. Estas opiniões derivam do seu entendimento do mundo e o indivíduo é um cidadão na medida em que é parte integrante desta mesma sociedade. No nosso trabalho analisamos exatamente a relação entre cidadania e rádio. A escolha deste medium deve-se ao fato de o rádio ser um dos primeiros veículos de comunicação de massa, e embora alguns teóricos tenham proclamado o seu fim, o rádio sobrevive e continua a desempenhar um papel importante nas sociedades. Consideramos o rádio como um veículo privilegiado para a promoção da cidadania. A nossa intenção foi, então, compreender como o rádio, hoje, manifesta o seu potencial, enquanto parte integrante dos mass media, de promoção do desenvolvimento da cidadania. A sua programação contribui para o entendimento de mundo indispensável à formação de opiniões sobre questões relevantes ao exercício da cidadania? Desta forma, analisamos a programação de seis rádios da cidade de Palmas $^{2}$ durante dois anos consecutivos, com o objetivo de verificar se a programação cotidiana das rádios em estudo promove o/a cidadão/a

\footnotetext{
2 Esta pesquisa foi desenvolvida com o apoio do Programa de Iniciação Científica da UFT e contou com a participação de sete alunos/as durante os dois anos de realização: Geíne Med rado Rodrigues; Heloísa Cipriano Lima; Isabela Caldas de Souza Leão; José Uendel Souza da Costa; Letícia Miranda Lucena; Lourranny Parente Silva e Lukas Ramos Franco. Também contou com o apoio técnico do servidor da UFT Idglan Souza Maia e do acadêmico Arinaldo Araújo da Silva.
}

João Pessoa - Brasil | ANO 7 VOL.7 N.1 | JAN./JUN. 2020 | p. 174-195 


\section{Aिए[ORA}

Valquíria Guimarães da SILVA

palmense, proporcionando conhecimento de seus direitos e deveres enquanto morador da cidade.

\section{Descrição da pesquisa}

A escolha da metodologia, enquanto caminho que possibilita a apreensão da realidade, combina uma abordagem qualitativa e uma abordagem quantitativa, desenvolvida no estudo de seis rádios de Palmas. A escolha das seis rádios para composição da pesquisa partiu, inicialmente, da localização da sede da rádio, todas com endereço em Palmas, embora a concessão não fosse para a capital tocantinense, como é o caso da rádio CBN Tocantins, que sua concessão é para a cidade de Porto Nacional, mas também incluímos a Rádio Líder FM $(95,7)$, que tem sua concessão para a cidade de Paraíso do Tocantins, por ser uma rádio com boa audiência em Palmas. Assim, as seis rádios que fizeram parte do estudo foram: Rádio Capital FM $(87,9)$, Rádio 96 FM $(96,1)$, Rádio UFT FM $(96,9)$, Rádio Líder FM $(95,7)$, Rádio CBN Tocantins FM $(101,9)$ e Rádio Jovem Palmas FM $(104,9)$.

O método de análise adotado para análise da grade de programação das rádios participantes da pesquisa insere-se nos princípios da análise de conteúdo entendida como:

[...] um conjunto de técnicas de análise das comunicações visando obter por procedimentos sistemáticos e objetivos de descrição do conteúdo das mensagens indicadores (quantitativos ou não) que permitam a inferência de conhecimentos relativos às condições de produção/receção (variáveis inferidas) destas mensagens (BARDIN, 2008, p. 44).

E especificamente para a análise de conteúdo jornalístico recorremosà compreensão de Herscovitz (2007, p. 126-127), que define esta análise como um "método de pesquisa que recolhe e analisa textos, sons, símbolos e imagens impressas, gravadas ou veiculadas em forma eletrônica ou digital encontrados na mídia a partir de uma amostra aleatória ou não dos objetos 
O RADIOJORNALISMO NA CIDADE DE PALMAS: uma análise da atuação de seis rádios sobre suas contribuições para cidadania

estudados". Para a autora, a análise de conteúdo é muito útil às pesquisas jornalísticas, pois contempla um amplo universo de aplicação.

A análise de conteúdo possibilita uma compreensão dos sentidos das comunicações, de seus conteúdos e significações explícitos ou ocultos, como bem explica Bardin (2008, p. 43), "[...] a tentativa do analista é dupla: compreender o sentido da comunicação (como se fosse um receptor normal), mas também e principalmente desviar o olhar para uma outra significação, uma outra mensagem [...]". É, atualmente, utilizada para estudar e analisar os materiais de forma qualitativa, procurando-se uma melhor compreensão de uma comunicação ou discurso, extraindo os aspectos mais relevantes, "a análise de conteúdo tenta compreender os jogadores ou o ambiente do jogo num momento determinado, com o contributo das partes observáveis. [...] procura conhecer aquilo que está por trás das palavras sobre as quais se debruça. [...] é uma busca de outras realidades através das mensagens" (BARDIN, 2008, p. 45).

A análise de conteúdo pode contemplar diversas formas de unidades de registro, como explica Fonseca Junior (2005, p. 294):

[...] as palavras-chaves de um discurso político, os personagens de um filme ou romance, os anúncios publicitários de uma revista, os acontecimentos de um período histórico, etc. Alguns textos sobre análise de conteúdo incorporam a esta modalidade as unidades de enumeração ou unidades espaço-temporais, como o minuto de emissão radiofônica, a sequência de um filme, o centímetro coluna das notícias dos jornais, etc.

Segundo Bardin (2008, p. 145-146), os critérios de categorização podem ser: semântico (categorias temáticas), sintático (categorias gramaticais - verbos, adjetivos, etc.), léxico (classificação das palavras segundo o seu sentido) e expressivo (categorias que classificam, por exemplo, as diversas "desordens" da linguagem).

Desta forma, a unidade de registo escolhida, por se tratar de programas radiofônicos, é o segundo; e o critério de categorização o semântico, partindo 


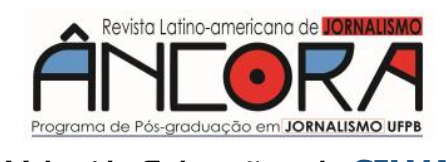

Valquíria Guimarães da SILVA

de categorias temáticas. Escolhemos o tema por o considerarmos a forma mais adequada para a codificação de toda a amostra da pesquisa. "Um tema é formado por uma unidade de texto que inclui o sujeito, o verbo e o objeto ou o agente, a ação e o alvo da ação" (HERSCOVITZ, 2007, p. 134). Entendemos que a análise de conteúdo é o método que melhor nos ajudou a entender quem produz e quem recebe a notícia - as suas motivações, intencionalidade, objetivos, efeitos, etc. Bardin (2008, p. 131) afirma ainda que "fazer uma análise temática consiste em descobrir os 'núcleos de sentido' que compõem a comunicação e cuja presença, ou frequência de aparição, podem significar alguma coisa para o objetivo analítico escolhido".

É importante frisar que o nosso estudo trabalhou tanto com uma pesquisa qualitativa, como com uma pesquisa quantitativa, por entendermos assim como Herscovitz (2007, p. 126) que "a necessidade de integração dos campos quantitativo e qualitativo decorre do reconhecimento de que os textos são polissêmicos - abertos a múltiplas interpretações por diferentes públicos e não podem ser compreendidosfora do seu contexto".

Para analisarmos se a programação da rádio contribui para o entendimento de mundo indispensável à formação de opiniões sobre questões relevantes ao exercício da cidadania e se promove, incentiva, os cidadãos a refletirem sobre as decisões políticas, sociais e do seu dia-a-dia, recorreremos a Marques de Melo (2010) e a Janine Lucht (2010), assim como a Chaparro (2000). Primeiramente, para diferenciar a programação das rádios em conteúdos jornalísticos e conteúdos não jornalísticos. Consideramos como conteúdos jornalísticos, os tipos propostosna classificação de Lucht (2010, p. 273-274) com relação aos gêneros radiojornalísticos, a saber: informativo, opinativo, interpretativo, utilitário e diversional. Todo o conteúdo restante das programações não classificados nestes gêneros, consideramos como conteúdo não jornalístico.

A decisão de separar os conteúdos jornalísticos dos não jornalísticos deve-se ao fato de reconhecermos que é através do jornalismo, mais 
essencialmente, que os meios de comunicação desenvolvem os seus conteúdos e contribuem para uma melhor compreensão de mundo; reconhecemos também o papel central que o jornalismo desempenha nas sociedades democráticas. E como afirma Jay Rosen (2003, p. 44-45), "o jornalismo pode e deve desempenhar um papel no fortalecimento da cidadania, no melhoramento do debate público e no reviver da vida pública".

As categorias temáticas que fazem parte da análise da programação radiofônica das seis rádios que compõem este estudo foram definidas a partir do entendimento da cidadania como uma construção da relação das pessoas com a sociedade em que vivem, assumindo o indivíduo o estatuto de cidadão na medida em que é parte integrante desta sociedade.

Escolhemos a semana de 27 de novembro a primeiro de dezembro de 2017 para realizarmos a gravação da programação das seis rádios, das cinco da manhã às $22 \mathrm{~h}$. Isto para o primeiro ano da pesquisa. Foi uma escolha metodológica não incluir a madrugada, por observarmos que a programação das rádios neste horário é composta em sua maioria de música, assim definimos este horário por ser o que contempla o maior número de programas jornalísticos de todas as rádios que compõem o nosso estudo. É importante frisar que embora a Rádio CBN Tocantins seja de notícias (all news) e não tenha música, parte da transmissão é em rede, ou seja, não é uma produção da Rádio CBN Tocantins. E o nosso trabalho foi analisar a produção das rádios locais, de modo que o conteúdo produzido pela rede não entrou na contagem de conteúdo jornalístico da CBN Tocantins. Também foi uma escolha metodológica não incluir o fim de semana. Ao observarmos a programação identificamos que os programas de notícia também se concentram durante a semana, entendemos, assim, que ao acompanharmos a programação das rádios de segunda à sexta-feira tivemos uma visão da contribuição ou não das emissoras para a cidadania dos palmenses.

João Pessoa - Brasil | ANO 7 VOL.7 N.1 | JAN./JUN. 2020 | p. 174-195 
Neste segundo ano da pesquisa seguindo a mesma metodologia, a nossa tentativa também foi o acompanhamento de 17 horas por dia de cada rádio, o que totalizaria 306 mil segundos para a semana de cada rádio. Mas, novamente, em função dessas pequenas perdas tivemos o maior tempo conseguido em uma rádio de 303.261 segundos e o menor com 274.020 segundos. $O$ fato de termos ampliado o tempo de acompanhamento e gravação nos permitiu a escolha dos melhores dias de captação, o que fez melhorarmos o quantitativo de segundos analisados do primeiro para 0 segundo ano da pesquisa. $O$ dia escolhido para a análise mais qualitativa dos temas trabalhados em cada rádio no conteúdo jornalístico foi o dia 30/11/2018, com exceção da Rádio Capital FM que o dia escolhido foi 14/11/2018. A escolha do dia para análise qualitativa foi em função do melhor dia captado em termos quantitativo (mais segundos) de cada rádio.

\section{Resultado e discussão}

$\mathrm{Na}$ análise dos dados do primeiro ano de pesquisa, que refere-se a semana de 27 de novembro a primeiro de dezembro de 2017, obtivemos os seguintes resultados: a partir dos dados coletados e transcritos, foi realizada a análise quantitativa e qualitativa da programação de todas as rádios estudadas nesta pesquisa. Para cada uma, foram separados os conteúdos jornalísticos do não jornalísticos, que vamos chamar de outros conteúdos. Após a separação dos conteúdos da programação das seis rádios, nota-se que a rádio UFT FM, que é uma rádio institucional da Universidade Federal do Tocantins, cuja principal proposta é trazer uma programação mais voltada para a educação e cultura, foi a emissora com a menor parcela de conteúdo jornalístico, totalizando, na semana analisada, apenas $8 \%$, enquanto os outros conteúdos da semana totalizaram $92 \%$ de todo conteúdo transmitido pela rádio, conforme podemos observar no gráfico a seguir, que apresenta também o resultado das outras rádios analisadas. 


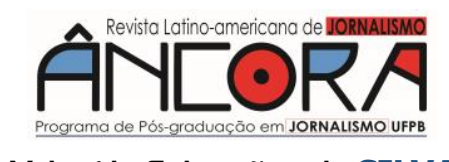

Valquíria Guimarães da SILVA

Figura 1 - Gráfico do primeiro ano de análise (2017)

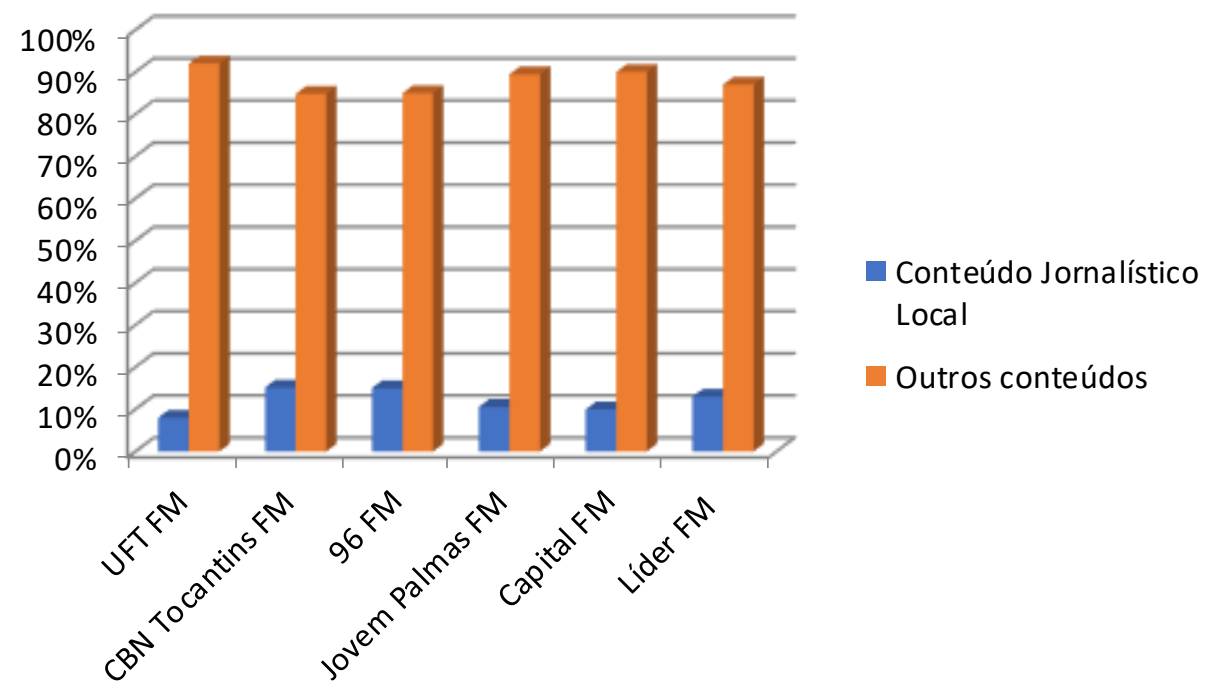

Fonte: Pesquisa de campo (2017), organizado pela autora (2020).

Para uma reflexão e exposição mais completa da pesquisa escolhemos um dia para analisar de forma qualitativa e quantitativa esse tempo destinado ao conteúdo jornalístico. No dia 29 de novembro de 2017 fizemos uma investigação mais minuciosa identificando quais assuntos foram abordados no conteúdo considerado informativo e quanto tempo foi destinado para cada assunto. A rádio $96 \mathrm{FM}$ dedicou $14 \%$ de sua programação neste dia para o conteúdo jornalístico, a Capital FM 11\%, a UFT FM 9\%, a CBN Tocantins 9,7\%, a Jovem FM 10,87\% e a Líder FM 12,87\%.

Com relação aos temas na rádio $96 \mathrm{FM}$ temos o maior destaque para o Esporte com $26 \%$ da programação do dia estudado. Outros pontos fortes são as pautas relacionadas à Sociedade, somando $18 \%$ do total, Prestação de Serviços totalizando $14 \%$. Saúde também aparece entre os assuntos mais presentes, tendo $12 \%$ do tempo de programação. Cultura e Emprego possuem $6 \%$ cada, Meio Ambiente $5 \%$ e Educação tem 4\%. Os tópicos com índices de tempo mais baixos no dia em questão são: Economia e Polícia, com 3\% cada, e por último, com $2 \%$ está o tema de Política. Na rádio UFT FM, as pautas com maior destaque no dia em questão foram as de Educação e Saúde, totalizando $42 \%$ e $39 \%$ do tempo dedicado ao conteúdo informativo, respectivamente. 
O RADIOJORNALISMO NA CIDADE DE PALMAS: uma análise da atuação de seis rádios sobre suas contribuições para cidadania

Outros temas abordados durante o dia foram: Política, com 8\%, Sociedade com 6\%, Cultura e Meio Ambiente com 2\% cada, e Prestação de Serviços, somando $1 \%$.

Já a Capital FM os temas com mais tempo na grade da programação da rádio foram Política e Sociedade, cada um com $16 \%$ do total. Saúde com 9\%, Educação $8 \%$ e Economia com 11\%. Os assuntos de Polícia possuem 4\% deste tempo, Meio Ambiente soma 3\%. Empatados com 2\% temos Cultura, Esporte e Prestação de Serviços. Por último, emprego, com 1\%. Com relação a CBN Tocantins temos: Esporte com 43,7\% seguido de Prestação de Serviço com 17\%. Economia com 9,3\%, Meio Ambiente 8,9\%, Saúde 8,8\% e Política $7,6 \%$ completam a lista dos temas com maior tempo. Os temas menos abordados foram: Sociedade 0,4\%, Educação 0,9\% e Polícia 3,4\%.

A rádio Jovem $\mathrm{FM}$ tem a seguinte relação dos temas mais abordados: Cultura (26,8\%), Sociedade (14,9\%), Saúde (12,3\%), Polícia (11,6\%) Política $(9,8 \%)$, Economia (7,6\%) e Esporte (6,9\%). Já os menos abordados foram: Meio Ambiente (1,7\%), Educação (2,7\%) e Prestação de Serviço (5,7\%). Já a Líder FM temos a seguinte ordem para os mais abordados: Esporte (37\%), Sociedade (16,8\%) Política (15,6\%) e Cultura (14,4\%). Os com menor tempo são: Educação (0,6\%), Internacional (0,9\%), Saúde (3,9\%) e Polícia (4\%).

$\mathrm{Na}$ análise referente ao segundo ano (2018) de acompanhamento da programação das rádios podemos verificar no gráfico a seguir que a rádio UFT FM, ficou com a segunda menor parcela de conteúdo jornalístico, totalizando, nos cinco dias analisados, apenas $5,6 \%$, enquanto os outros conteúdos totalizaram $94,4 \%$ de todo conteúdo transmitido pela rádio. Embora neste segundo ano de pesquisa a UFT FM tenha melhorado seu desempenho com relação as outras rádios, é importante ressaltar que houve uma diminuição significativa da produção de conteúdo jornalístico produzido pela rádio.

João Pessoa - Brasil | ANO 7 VOL.7 N.1 | JAN./JUN. 2020 | p. 174-195 184 


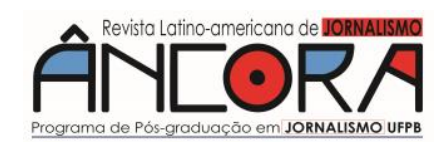

Valquíria Guimarães da SILVA

Figura 2 - Gráfico do segundo ano de análise (2018)

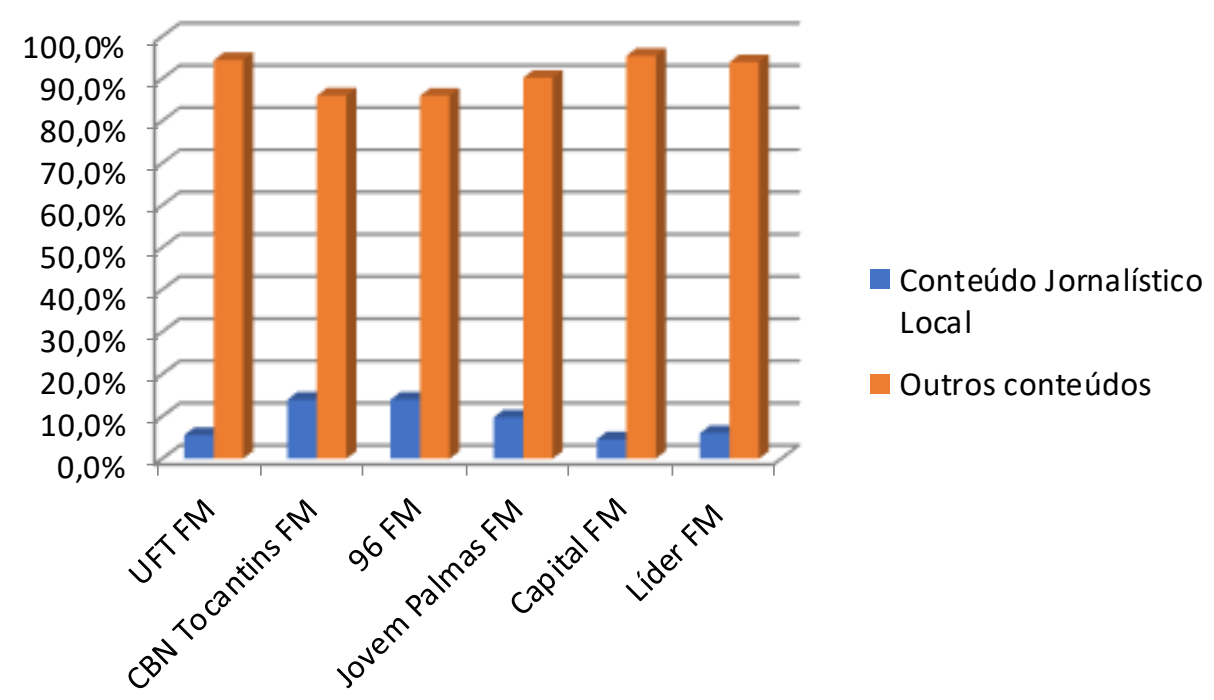

Fonte: Pesquisa de campo (2018), organizado pela autora (2020).

Também para o segundo ano da pesquisa escolhemos um dia para analisar de forma qualitativa e quantitativa esse tempo destinado ao conteúdo jornalístico. No dia 30 de novembro de 2018, com exceção da rádio Capital FM que a análise foi no dia 14 de novembro de 2018, fizemos uma investigação mais minuciosa, identificando quais assuntos foram abordados no conteúdo considerado jornalístico e quanto tempo foi destinado para cada assunto. A rádio 96 FM dedicou $14,53 \%$ de sua programação neste dia para o conteúdo jornalístico, a UFT FM 7\%, a CBN Tocantins 12,47\%, a Jovem FM 12,25\% ea Líder FM 6\%. Já a Capital FM dedicou 5,5\% da sua programação do dia 14/11/2018 para conteúdos jornalísticos.

No que tange os assuntos específicos, a UFT FM dedicou 44\% (quarenta e quatro) do seu tempo à pautas de sociedade. Ou seja, foram 1.982 (mil novecentos e oitenta e dois) segundos dedicados aos assuntos de cunho social. O restante do tempo se dividiu entre saúde $(28 \%)$, prestação de serviço $(14 \%)$, policial (9\%), economia (2\%), cultura (2\%) e esporte (1\%).

Quando comparados aos dados do primeiro ano da pesquisa, podemos notar que houve uma diminuição no tempo disponibilizado para informação, uma diferença de $2 \%$ (dois por cento). Outra mudança que ocorreu de um 
ano para outro foram o tempo dos temas abordados. No primeiro ano, os destaques foram educação e saúde, com $42 \%$ (quarenta e dois por cento) e $39 \%$ (trinta e nove por cento) do tempo, respectivamente. Enquanto no segundo, sociedade e saúde ganharam mais tempo de informação. É possível notar que os assuntos tratados durante a programação também se modificaram. Enquanto no primeiro ano, política e meio ambiente estavam presentes nos boletins, ocupando, respectivamente, $8 \%$ (oito por cento) e $2 \%$ (dois por cento) da programação, a pauta esporte entrou nos boletins do segundo ano, e política e meio ambiente saíram.

Quanto à utilização ou não de fontes especializadas para corroborar as informações transmitidas, foi feito um estudo após a finalização da transcrição completa do dia escolhido. Foi possível perceber que esse tópico permaneceu inalterável: a UFT FM faz um grande uso de fontes, buscando enriquecer seu conteúdo, seja por meio de entrevistas com fontes especializadas, ou apenas citando-as de maneira indireta. Os programas editoriais, e programas como o Cuide-se Bem e o Repórter Calango (programa experimental dos estudantes de Jornalismo da UFT), apresentam uma quantidade significativa, inclusive, aproveitando como forma de expandir o ambiente de conhecimento no qual ela se encontra. O UFT Notícia, boletins informativos distribuídos em horários diferentes ao longo da programação, também utiliza essas fontes, menos em forma de entrevistas, mais como uma forma de passar seriedade/credibilidade às informações.

A Rádio 96 FM tem uma programação variada e aborda diversos temas, porém o maior destaque é dado ao esporte, uma vez que há um jornal inteiro dedicado à este tema, tomando 19\% da programação do dia estudado. Cultura foi a segunda temática mais trabalhada, com $16,3 \%$. Outras pautas bastante veiculadas estão relacionadas à sociedade, somando $13,8 \%$ do total, meio ambiente com $13 \%$, polícia $12 \%$ e saúde totalizando $11,4 \%$ da programação

João Pessoa - Brasil | ANO 7 VOL.7 N.1 | JAN./JUN. 2020 | p. 174-195 186 


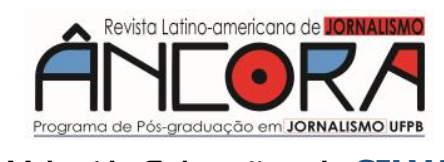

Valquíria Guimarães da SILVA

informativa. Economia possui 6,1\%, emprego 3,5\%, educação 2,2\%, política $1,6 \%$ e por último prestação de serviço com $1,1 \%$.

Já a rádio Líder FM, tem a maior parte do conteúdo veiculado comprado de um grupo chamado Talk Rádio de Programação. Os únicos programas que não são comprados desse grupo são o Tribuna Paraíso, Líder Esporte e os comerciais do Governo do Tocantins e do município de Paraíso. Nos 6\% da programação informativa da Líder FM, foi possível perceber que o tema mais abordado também é o esporte, com 20,4\% da programação diária. Para os demais assuntos abordados temos a seguinte ordem: sociedade 16,9\%, cultura $15,9 \%$ e política $15 \%$, saúde $9,5 \%$, economia $8,2 \%$ e polícia com $6,2 \%$. As pautas menos trabalhadas são: educação 3,5\%, prestação de serviço 2,9\%, meio ambiente $0,8 \%$ e emprego $0,7 \%$.

No dia escolhido para a análise, a rádio CBN TocantinsFM destinou para o conteúdo informativo 7.487 segundos $(12,47 \%)$ da programação, o equivalente a apenas pouco mais que duas horas de programação. Vale ressaltar que o período escolhido para a captação de áudios foi o mesmo período onde muitos estados brasileiros, na época, entravam em horário de verão, entre eles o estado de São Paulo, onde é produzido o conteúdo em rede da CBN, por isso, a programação da rádio deveria ser adiantada em uma hora também no Tocantins, mesmo o Estado não entrando no horário de verão. No entanto, foi uma decisão da coordenação da CBN Tocantins perder uma hora do programa local, após avaliar que a programação da rádio acompanha a rotina do ouvinte pela manhã, e por isso, adiantar em uma hora a programação regional poderia afetar na audiência da rádio. Vale ressaltar que em 2017 não houve essa diminuição de tempo da programação regional.

Diante disso, o programa regional que iria ao ar das nove horas da manhã ao meio dia, de segunda a sexta-feira, durante o horário de verão ficou com uma hora a menos, terminando às 11 horas da manhã. Os temas mais trabalhados no dia em questão foram: Prestação de Serviços (16,68\%); Educação (15,91\%); Saúde (13,93\%), Esporte (12,27\%) e Polícia (11,33\%). 
Já os temas menos abordados foram: Meio Ambiente (1,12\%); Cultura $(3,41 \%)$, Economia (5,92\%), Sociedade (6,54\%) e Política (7,89\%).

No ano de 2017 o assunto mais abordado foi esporte tomando $43 \%$ da programação, já no de 2018 esporte ainda é um dos assuntos mais abordados, porém, com uma porcentagem bem menor de 12,27\%. O tema Educação teve um aumento significativo, em 2017 não chegou a 1\% da programação, já em 2018 ocupa 15,91\%. O tema Política manteve praticamente a mesma porcentagem, em 2017 chegou a 7,6\% e em 2018 7,89\%. Prestação de Serviço em 2017 o tema ocupava 17\% da programação, já em 2018 ocupou 16,68\%. Economia também caiu em 2018 ocupando 5,92\% da programação regional, enquanto em 2017 ocupava 9,3\%. Saúde tomava 8,8\% da programação em 2017 e teve um aumento ocupando agora 13,93\% da programação. O tema Polícia teve um grande aumento, em 2017 ocupava 3,4\% da programação, já em 2018 subiu para 11,33\%. Meio Ambiente caiu significativamente sendo que em 2017 ocupava 8,9\% da programação e em 2018 ocupou apenas 1,12\%. Sociedade aumentou em 2018, pois em 2017 o tema não chegou a ocupar 1\% da programação, estava com 0,4\% e em 2018 ocupa 6,54\%. O tema Cultura não chegou a ser abordado na programação no dia 29 de novembro de 2017, já em 2018 ocupou 3,41\% da programação.

A rádio Jovem Palmas FM distribuiu o conteúdo jornalístico nos seguintes temas: Saúde com 12\%; Polícia com 3\%; Economia com 1\%; Educação com 2\%; Cultura com 2\%; Outros assuntos com 2\% e os destaques foram nas pautas de Sociedade com 36\%; Prestação de Serviço e Política com $20 \%$. Comparando os dados do primeiro ano e do segundo ano observamos de forma mais consolidada os dados no que se refere a contribuição das rádios na cidadania. No caso da Jovem Palmas FM, observamos que na semana analisada em 2017 a rádio apresentou 11\% de conteúdo informativo e na semana analisada no ano posterior, foram apresentados $9,8 \%$ de conteúdo informativo. Dessa forma houve uma queda do ano de 2017 para o de 2018,

João Pessoa - Brasil | ANO 7 VOL.7 N.1 | JAN./JUN. 2020 | p. 174-195 188 


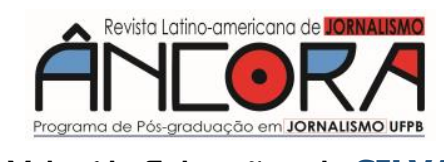

Valquíria Guimarães da SILVA

de forma que, embora seja uma queda quase irrelevante, mostra, assim, que a rádio continua a dedicar pouco tempo para o conteúdo jornalístico, mantendo sua programação pautada muito mais no entretenimento. A rádio Jovem Palmas FM, apresenta um crescimento no tempo dedicado ao conteúdo informativo no dia escolhido para a análise qualitativa, embora na soma semanal tenha havido uma pequena queda. No dia analisado em 2017, primeiro ano de pesquisa, foram $10,87 \%$ do conteúdo voltado a contribuição da cidadania, já no dia analisado em 2018, segundo ano da pesquisa, foram apresentados $12,25 \%$ do conteúdo contribuindo com a cidadania. Desse conteúdo informativo apresentado é possível visualizar que a diversidade de pautas é mantida, o que possibilita uma análise de que a rádio mantém a sua programação sem muitas mudanças e a problemática de fontes não especializadas ainda se repete na programação.

No caso da Capital FM houve uma menor diversidade de pautas abordadas. A pauta em destaque foi Política com 50\%; seguido de Sociedade e Economia com respectivamente 15\% e 14\%; também Saúde com 12\%; Meio Ambiente com 4\% e Prestação de Serviço com 5\%. No primeiro ano de pesquisa foi concluído que na semana analisada $10 \%$ da programação foi dedicada a conteúdo informativo para os ouvintes. No segundo ano de pesquisa com a análise dos áudios foi concluído que a rádio dedicou apenas 4,6\% do tempo para apresentar conteúdo informativo. Assim, há uma queda significativa, pouco mais da metade de um ano para o outro. Algo que evidencia o desperdício do potencial do processo comunicacional que a rádio possui. Nas análises de temas abordados no conteúdo informativo apresentado, é possível notar também que a diversidade de pautas na Capital FM diminuiu do primeiro ano da pesquisa para o segundo, de 12 abordagens em 2017 para seis abordagens em 2018. A Política se mantém como um dos principais temas, com 50\% do dia analisado em 2018 e $16 \%$ do dia analisado em 2017. Desse modo alguns temas deixaram de ser abordados com a diminuição do tempo dedicado ao conteúdo informativo e o aumento 
significativo do tema política. A rádio Capital FM se dedica mais ao entretenimento, e os boletins informativos com apresentação de fontes com potencial não oficial é apresentando em maior grau.

Percebemos que a atuação das rádios no tocante à sua contribuição para aspectos que fazem parte do cotidiano dos ouvintes, da construção da cidadania, é passível de questionamento. Observamos que, de maneira geral, o conteúdo não jornalístico suplanta o conteúdo jornalístico, e o conteúdo jornalístico não tem dado ênfase, de maneira geral, às questões mais ligadas às pessoas, à cidadania. $O$ jornalismo tem deixado de ser um elemento de ligação, "este espaço aberto a toda e qualquer manifestação dos agentes sociais" e "a notícia, como mercadoria, vai recebendo cada vez mais investimento para melhorar sua aparência e sua vendabilidade [...]" (MARCONDES FILHO, 2002, p. 32-24). E, desse modo, o rádio está perdendo a oportunidade de desenvolver um jornalismo que contribua para 0 aprofundamento e a consolidação de uma sociedade cidadã.

O rádio é dos meios de comunicação de massa mais antigos e continua a mostrar a sua grande capacidade de resistência e adaptabilidade. Mas é necessário repensar a construção da sua programação em termos de conteúdos. O rádio, pela sua própria constituição e essência, deveria ser um espaço de livre expressão dos sujeitos, um espaço aberto a atividades diversas da sociedade organizada. Poderia estimular a reflexão dos ouvintes, por meio de uma programação que envolvesse mais debates, reportagens, análises, informações contextualizadas e aprofundadas. Mas, de maneira geral, não foi essa a programação que encontramos, no nosso estudo, nas rádios pesquisadas.

\section{Considerações finais}

Ao finalizarmos a pesquisa foi possível perceber que as seis rádios em questão têm maior tempo dedicado a outros conteúdos. Durante os dois períodos que escolhemos para análise, tanto em 2017 como em 2018,

João Pessoa - Brasil | ANO 7 VoL.7 N.1 | JAN./JUN. 2020 | p. 174-195 190 


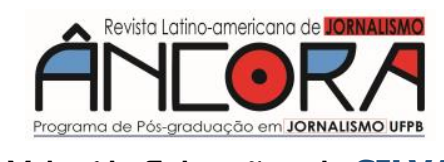

Valquíria Guimarães da SILVA

nenhuma rádio chegou a dedicar quatro horas diárias de conteúdo jornalístico. Somando todo o tempo dedicado ao conteúdo jornalístico a rádio que dedicou maior espaço chegou apenas a $15,15 \%$ da programação semanal e isto foi no primeiro ano da pesquisa, já no segundo ano a rádio que dedicou maior tempo na soma do período analisado foi de 14,04\%. Ainda percebemos uma falta de estrutura para o desenvolvimento de uma produção e tratamento de notíáas mais contextualizadas e com uma profundidade maior, que possam contribuir com a cidadania.

A questão comercial ocupa hoje um lugar de destaque na condução dos meios de comunicação em geral e com relação às rádios, isso não é diferente e a programação acaba subordinada a esta dinâmica. E assim os ouvintes são vistos mais como consumidores potenciais do que como um público de cidadãos. Desta forma, percebemos que a programação desenvolvida pelas rádios em questão não prioriza o compromisso com interesses sociais, é mais pautada por critérios de audiência, cujo fimé muito mais o entretenimento do que qualquer contribuição de interesse público.

Como podemos perceber através da análise quantitativa e qualitativa das rádios em questão, os outros conteúdos suplantam o conteúdo jornalístico. Todas as rádios dedicam maior tempo de sua programação ao conteúdo não jornalístico e o conteúdo jornalístico ainda é falho no quesito de temas relacionados à cidadania. Também observamos uma falta de pluralidade de vozes nos próprios temas que foram desenvolvidos.

A rádio UFT FM, como uma rádio educativa, ainda deixa a desejar em seu papel de formação do senso crítico dos ouvintes. Isso porque, apesar de seus boletins informativos e programas editoriais terem uma base bem construída, o tempo dedicado ao conteúdo não informativo ainda é mais alto do que o disponível para o informativo, produzido regionalmente. No caso da UFT FM, em específico, não há o que se falar em interesse mercadológico. Por ser uma rádio pública e universitária, sua programação não pode conter comerciais pagos. No entanto, a rádio não favorece, como deveria, a 
divulgação de informações ou de conteúdos educativos, prioriza o entretenimento - aqui, na forma de programação musical. A UFT FM precisa cumprir seu papel como rádio universitária e educativa. É imprescindível a valorização da sua contribuição no interesse público, a fim de participar mais ativamente da construção da cidadania.

A rádio $96 \mathrm{FM}$ cumpre um pouco melhor seu papel enquanto rádio pública também, tem mais tempo e diversidade de temáticas à serviço da comunidade em sua grade diária. Mas, assim como a UFT FM, teve redução do conteúdo jornalístico ao compararmos as análises de 2017 (15\%) e 2018 (14,04\%). Assim como a UFT FM, a 96 FM, por ser uma rádio pública, não há o que se falar em interesse mercadológico. Esperávamos encontrar um conteúdo jornalístico maior e mais qualificado do que encontramos.

A rádio Líder FM chega a ter uma programação variada, no entanto, sabe-se que os programas não são produzidos pela equipe da rádio, são comprados e apenas veiculados, outras vezes as notícias transmitidas são retiradas de sites locais. Outro ponto a se destacar foi a redução do conteúdo informativo para menos da metade do registrado no primeiro ano da pesquisa em relação à programação semanal. Em 2017 o percentual foi de 13\% e em 2018 caiu para $6,07 \%$.

Foi possível perceber que a rádio CBN Tocantins destina pouco tempo de sua programação para as informações regionais. Na análise qualitativa detectamos que em uma rádio que toca 24 horas de notícias a programação regional chegou a ocupar apenas três horas da programação em rede, isso para o primeiro ano da pesquisa, já no segundo ano esse tempo foi reduzido, por uma opção da rádio em consequência do horário de verão. Foi possível perceber também que não existe uma preocupação da rede CBN em preservar esse espaço das afiliadas regionais em situações como o horário de verão (nem todas as regiões do país seguiam o horário de verão), fazendo com que a rádio ou se adapte a programação nacional ou perca ainda mais tempo da sua

João Pessoa - Brasil | ANO 7 VOL.7 N.1 | JAN./JUN. 2020 | p. 174-195 192 


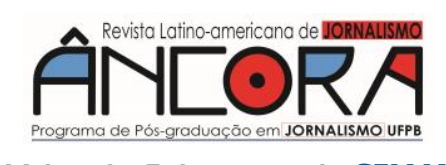

Valquíria Guimarães da SILVA

programação regional. Percebemos que houve uma mudança na distribuição de temas da CBN Tocantins, o que fez com que a programação ficasse bem mais diversa, incluindo temas que não foram abordados no ano de 2017, porém, foi possível perceber também que a rádio não tem tanto apelo popular, e se aproxima mais de um público mais elitizado, tratando bastante temas de cunho empresarial e econômico, mesmo quando abordava temas de prestação de serviço eram assuntos mais voltados para pequenos empresários e em nenhum momento uma pauta voltada para a comunidade e por não pautar esses assuntos também não utiliza personagens que falem pela comunidade, na maioria das pautas as fontes são oficiais ou especialistas no assunto. Sendo assim, é possível afirmar que a rádio CBN Tocantins neste período em que foi analisada de 2017 a 2018 não representou de forma significativa à comunidade em que está inserida e mesmo sendo uma rádio que não traz o entretenimento em sua grade não contribuiu para a construção da cidadania de uma parcela da população, que não se viu representada no noticiário deste veículo e não teve sua voz ouvida.

Na rádio Capital FM, no primeiro ano de pesquisa foi concluído que na semana analisada $10 \%$ da programação foi dedicada a conteúdo informativo para os ouvintes. No segundo ano de pesquisa com a análise dos áudios foi concluído que a rádio dedicou apenas $4,6 \%$ do tempo para apresentar conteúdo informativo. Assim, há uma queda de pouco mais da metade de um ano para o outro. Algo que evidencia o desperdício do potencial do processo comunicacional que a rádio possui. A Capital FM possui um viés mais voltado ao entretenimento em uma avaliação da sua programação.

A rádio Jovem Palmas FM possui conteúdo com um enfoque regional. Apresentou um crescimento de $1,38 \%$ no tempo dedicado ao conteúdo informativo no dia escolhido para a análise qualitativa, embora na soma semanal tenha havido uma pequena queda $(0,76 \%)$. No dia analisado em 2017, primeiro ano de pesquisa, foram $10,87 \%$ do conteúdo voltado a contribuição da cidadania, já no dia analisado em 2018, segundo ano da 
pesquisa, foram apresentados $12,25 \%$ do conteúdo contribuindo com a cidadania. Desse conteúdo informativo apresentado é possível visualizar que a diversidade de pautas foi mantida, o que possibilita uma análise de que a rádio mantém a sua programação sem muitas mudanças.

Ao finalizarmos a pesquisa destacamos maior dedicação das rádios ao conteúdo não informativo. Poucas horas do dia foram dedicadas ao conteúdo informativo, analisando os dias escolhidos de cada rádio tanto no primeiro ano (2017) da pesquisa quanto no segundo ano (2018), observamos que muitas rádios dedicaram apenas uma hora do dia ao conteúdo informativo, às vezes até menos, e só uma passou de três horas por dia de conteúdo jornalístico.

É perceptível uma dificuldade na produção e tratamento de notícias mais contextualizadas e com uma pluralidade de vozes, que possam contemplar mais na contribuição com a cidadania. Também destacamos a dedicação do meio radiofônico a questão comercial, onde os ouvintes são tratados mais como um público potencial de consumidores do que cidadãos. $\mathrm{Na}$ esteira da globalização, das megacorporações, da mercantilização mediática, o público é meramente consumidor, e a qualidade passa a ser inversamente proporcional aos custos. Não se pode falar mais de uma especificidade, de um jeito próprio de trabalhar em rádio, atendendo a uma linguagem e dinâmicas particulares, o que se ensina como teoria tem sido colocado em xeque o tempo todo. Não é uma questão apenas de tecnologia. Mais que isso, é uma crise que afeta desde os modos de operação e produção até aos processos jornalísticosem si.

Notamos que o rádio, enquanto mídia jornalística é substancial para a população, principalmente às pessoas mais velhas ou de menor poder aquisitivo e vulnerabilidade social, e que por meio das ondas radiofônicas ainda há um grande potencial para o processo comunicacional jornalístico. 0 rádio, do nosso ponto de vista, ao tomar sentido do seu caráter de proximidade com

João Pessoa - Brasil | ANO 7 VOL.7 N.1 | JAN./JUN. 2020 | p. 174-195 


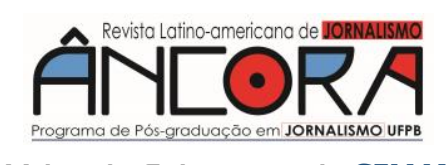

Valquíria Guimarães da SILVA

o ouvinte e desenvolvendo uma programação mais ativa e participativa, poderia certamente ser um importante instrumento de promoção da cidadania.

\section{Referências}

BARDIN, Laurence. Análise de Conteúdo. Lisboa: Edições 70, 2008. BONIXE, Luís. A Informação Radiofónica: rotinas e valores-notícia da reprodução da realidade na rádio portuguesa. Lisboa: Livros Horizonte, 2012.

CARMO-ROLDÃO, Ivete Cardoso do. A Função do Rádio Educativo no Brasil. In CARNICEL, Amarildo; FANTINATTI, Márcia (orgs.).

Comunicação e cidadania: possibilidades e interpretações. CampinasSP: CMU Publicações, 2008.

CHAPARRO, Manuel Carlos. Sotaques d'Aquém e d'Além Mar:

percursos e géneros do jornalismo português e brasileiro. Santarém: Edições Jortejo, 2000.

FONSECA JUNIOR, Wilson Corrêa da. Análise de Conteúdo. In DUARTE, Jorge; BARROS, Antonio (orgs.). Métodos e Técnicas de Pesquisa em Comunicação. São Paulo: Atlas, 2005.

HABERMAS, Jürgen. A Ética da Discussão e a Questão da Verdade. São Paulo: Martins Fontes, 2007.

HERSCOVITZ, Heloiza Golbspan. Análise de Conteúdo em Jornalismo. In LAGO, Cláudia; BENETTI, Marcia (orgs.). Metodologia de pesquisa em jornalismo. Petrópolis, RJ: Vozes, 2007.

LUCHT, Janine Marques Passini. Gêneros no Radiojornalismo. In MELO, José Marques de; ASSIS, Francisco de (orgs.). Gêneros jornalísticos no Brasil. São Bernardo do Campo: Universidade Metodista de São Paulo, 2010.

MARCONDES FILHO, Ciro. Comunicação e Jornalismo. A saga dos cães perdidos. São Paulo: Hacker Editores, 2002.

MELO, José Marques de. Gêneros Jornalísticos: conhecimento brasileiro. In MELO, José Marques de; ASSIS, Francisco de (orgs.). Gêneros

Jornalísticos no Brasil. São Bernardo do Campo: Universidade Metodista de São Paulo, 2010.

PERUZZO, Cecília (1998). Comunicação nos Movimentos Populares:

a participação na construção da cidadania. Petrópolis-RJ: Vozes, 1998. ROSEN, Jay. Tornar a Vida Pública Mais Pública. In TRAQUINA, Nelson; MESQUITA, Mário (orgs.). Jornalismo cívico. Lisboa: Livros Horizonte, 2003.

TAVARES, Denise. Brasil, 10 anos depois: identidade e história via TV. In CARNICEL, Amarildo; FANTINATTI, Márcia (orgs.). Comunicação e cidadania: possibilidades e interpretações. Campinas-SP: CMU Publicações, 2008.

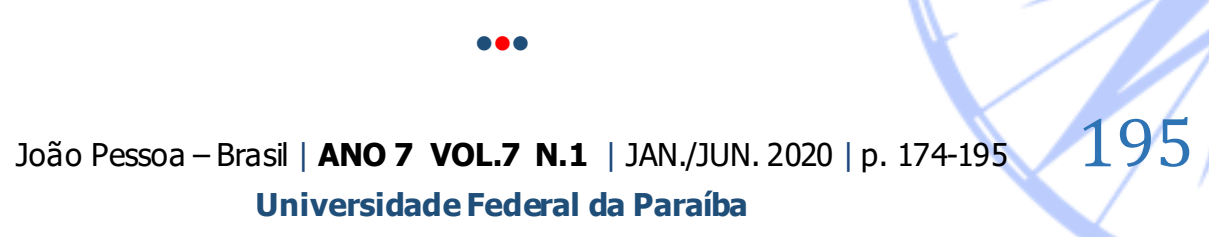

